\title{
ANÁLISE DOS MODELOS DE CURSO DE FORMAÇÃO PARAA DOCÊNCIA NO ENSINO SUPERIOR DA UFG/REGIONAL JATAÍ
}

\author{
Lázara Cristhiane de Assis Santana ${ }^{1}$ \\ Sandra Aparecida Benite Ribeiro ${ }^{2}$
}

\begin{abstract}
RESUMO: O curso de formação à docência é obrigatório para todos os docentes ingressantes na Universidade Federal da Goiás, que não comprovem experiência prévia no ensino superior. No decorrer dos anos, de 2001 a 2016, muitas alterações foram feitas no modelo do curso com o intuito de melhor atender às necessidades e reinvindicações dos docentes da Regional Jataí (REJ). Assim, o presente estudo teve como objetivos apresentar os modelos de cursos realizados neste período e analisar as críticas dos docentes desta Regional, de forma a fornecer subsídios para a estruturação dos cursos ou de programas de formação de docentes da futura Universidade Federal de Jataí. Os dados foram obtidos dos arquivos da Pró-Reitoria de Graduação em Goiânia e da Coordenação de Graduação da REJ, utilizando-se como instrumento de análise a matriz SWOT e o instrumento de avaliação institucional do MEC. A partir das análises documentais observamos que os modelos mais antigos de cursos, realizados somente com aulas expositivas por docentes externos à Regional Jataí não atendia os anseios dos docentes desta regional, que reagiam com críticas negativas. Somente a partir do ano de 2015, quando houve maior autonomia da Coordenação de Graduação para a organização do curso e maior participação dos docentes da REJ na execução do curso que novos delineamentos começaram a surgir. Em 2016, quando a Coordenação de Graduação e os docentes locais assumiram o curso e propuseram um modelo mais aplicado ao dia a dia do docente e com atividades práticas, as críticas foram positivas. Desta forma, a avaliação do docente é de grande valia no processo de construção de estratégias e de modelos para formação para a docência no ensino superior. Diante deste cenário, o processo de formação do docente na REJ satisfaz aos critérios de avaliação do MEC.
\end{abstract}

Palavras-chave: Curso de Docência. Estágio Probatório. Formação de professores.

\section{ANALYSIS OF MODELS FOR TEACHING TRAINING COURSES IN HIGHER EDUCATION OF UFG/ REGIONAL JATAÍ}

\begin{abstract}
The teaching training course is compulsory for all incoming professors at the Universidade Federal de Goiás (UFG), for those not having previous experience in higher education. Over the years, from 2001 to 2016, many changes were made to courses in order to better meet the needs and demands of UFG, Regional Jataí's (REJ) professors. Thus, the present study bears two objectives: (1) to present the

\footnotetext{
${ }^{1}$ Mestre em Administração pela Faculdade de Estudos Administrativo de Minas Gerais, graduada em Pedagogia pela Universidade Federal de Goiás. Técnica em Assuntos Educacionais da Universidade Federal de Goiás. cris_assis@hotmail.com

${ }^{2}$ Pós-doutorado pela Universidade do Porto, FADEUP, Portugal, em Fisiologia. Doutorado e mestrado em Ciências Biológicas (Zoologia) pela Universidade Estadual Paulista Júlio de Mesquita Filho. Graduado em Ciências Habilitação em Biologia pela Universidade Estadual Paulista Júlio de Mesquita Filho. Professora da Regional Jataí UFG. sandrabenite@gmail.com
} 
REVISTA ELETRÔNICA

DA GRADUAÇÃO/PÓS- LEADUAÇÃo EM EDÜCAÇÃO

UFG/REJ

models of courses carried out in this period and (2) to analyze the criticism from UFG, Regional Jataís professors. Based on that, we aimed to subsidize the structuring of the future Universidade Federal de Jataí's (UFJ) courses and teaching training programs. Data related to courses were obtained from the ProRectory of Undergraduate Studies in Goiânia and REJ's Coordination of Undergraduate Studies archives, and as analysis instruments we have used the SWOT matrix and the institutional evaluation tool of the Ministry of Education (MEC). From data analysis, we realized that previous courses, carried out only with lectures by professors, external to UFG/REJ, did not meet the expectations of REJ's professors, leading to considerable negative criticisms. It was only from 2015 on, when REJ's Coordination of Undergraduate Studies had greater autonomy to organize the teaching courses, and more REJ's professors could take part in its execution, that constructive criticisms began to emerge. In 2016, when REJ's Coordination of Undergraduate Studies and local professors took part in the course and proposed a more contextualized model with practical activities, critics became more positive. Thus, we conclude that professors' critical evaluation is of great value in constructing strategies and models for teaching trainings in higher education institutions. We also conclude that teaching trainings at UFG/REJ meet the evaluation criteria of MEC.

Key-words: Teaching Degree. Probationary Internship. Teaching training.

\section{INTRODUÇÃO}

O Curso Docência no Ensino Superior - Estágio Probatório foi criado, na UFG, no ano de 2001 atendendo ao disposto no Art. $4^{\circ}$ da Resolução Nº. 01/2001/CONSUNI:

Art. $4^{\circ}$ - Ao tomar posse, o docente que não comprovar experiência mínima de dois anos consecutivos de magistério em Instituição Federal de Ensino Superior, deverá participar do programa de atividades relativas à política de ensino, pesquisa e extensão e da gestão acadêmica da UFG e sua inserção na realidade, promovidas e regulamentadas pelo PróReitoria de Graduação. (UFG, 2001).

A partir da publicação de tal Resolução, a Pró-Reitoria de Graduação (PROGRAD) estruturou e promoveu, anualmente, cursos destinados aos docentes recém-admitidos pela instituição e que não possuíam experiências anteriores em Instituições Federais de Ensino Superior (IFES), com o intuito de fornecer instrumentos de formação que proporcionassem uma visão ampliada sobre o Ensino Superior, sobre a realidade da Universidade Federal de Goiás e sobre as práticas docentes adotadas individual ou coletivamente por professores de nível superior. Assim, o Curso de Docência - Estágio Probatório tem como objetivo geral, a consolidação de uma concepção mais ampla de formação profissional e docente na instituição, subsidiando os professores para o exercício da docência, destacando a relação teoria e prática e a articulação 
REVISTA ELETRÔNICA

DA GRADUAÇÃO/PÓS-CEADUAÇÃO EM EDÜCAÇÃO UFG/REJ

ensino e pesquisa (UFG, 2001). Para o cumprimento do estágio Probatório e para as progressões ou promoções na carreira docente, até o momento da conclusão deste estudo, era obrigatória a apresentação do certificado deste curso. No decorrer dos anos, houve alterações no modelo do curso, em sua carga horária e na forma de ministrá-lo, decorrentes das análises das críticas dos docentes obrigados a fazerem o curso, que geralmente não aprovavam o modelo do curso na Regional Jataí. Em decorrência dessas alterações, no ano de 2015 houve uma melhor aceitação do curso de formação docente e em 2016 as avaliações foram em sua maioria positivas.

Assim, o presente estudo teve como objetivo apresentar os formatos dos Cursos de Formação Docente realizados na Regional Jataí nos anos de 2001 a 2016 e fazer uma análise dos seus pontos fortes e de suas fragilidades, almejando fornecer subsídios para a estruturação de um curso ou de um processo de formação do docente de nível superior que atuará na Universidade Federal de Jataí.

\section{MÉTODOS}

Para a realização do presente estudo foram feitas análises documentais presentes na Coordenação de Graduação (COGRAD) e na Pró-Reitoria de Graduação (PROGRAD). As análises levaram em consideração as avaliações feitas pelos docentes a cada módulo do curso, a matriz SWOT (MEDEIROS, 2016) e o Instrumento de Avaliação Institucional do MEC (MEC, 2016, p. 18).

\section{RESULTADOS E DISCUSSÃO}

No ano de 2001, o Curso de Docência era ministrado exclusivamente por docentes veteranos da UFG, lotados em Goiânia, que geralmente ocupavam cargos administrativos importantes, os quais se deslocavam da capital goiana para ministrar aulas em todos os Câmpus (hoje denominados de Regionais), além de ministrar também no Câmpus sede; apresentava uma carga horária de 56 horas distribuídas semanalmente e uma estrutura rígida, tradicionalista, conforme descrito no Plano de Curso (Tabela 1) a seguir: 


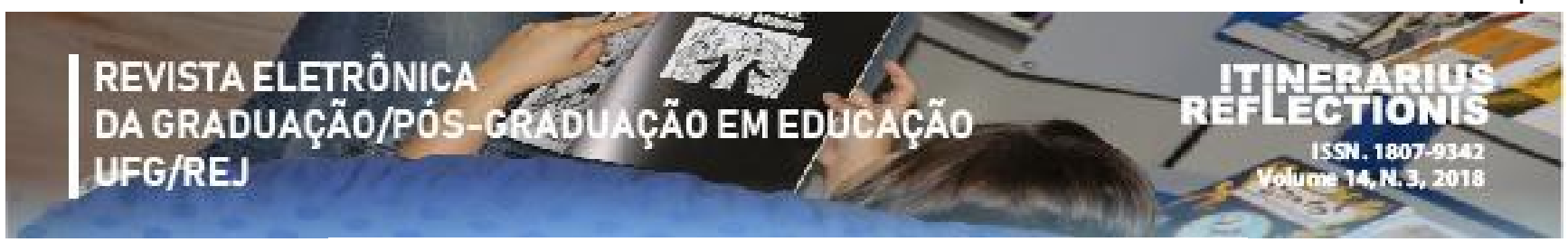

Tabela 1 Plano de Curso: Curso de Docência - Estágio Probatório (2001)

\section{JUSTIFICATIVA}

O Art. $4^{\circ}$. da Resolução no. 01/2001/CONSUNI, prevê que o docente ingressante da UFG, que não tenha experiência mínima de dois anos consecutivos de magistério em IFES, ao tomar posse, deverá participar de um programa de atividades relativas à política de ensino, pesquisa e extensão e da gestão acadêmica da UFG, promovidas e regulamentadas pela Pró-Reitoria de Graduação.

A Pró-reitoria de Graduação, em cumprimento a essa exigência tem promovido, anualmente, cursos para professores ingressantes na UFG, buscando propiciar instrumentos de formação que permita ao professor um olhar amplo sobre o Ensino Superior e sobre a realidade da UFG, bem como sobre as práticas docentes que realiza e que realizam o coletivo de professores de nível superior.

O objetivo desse Projeto é consolidar uma concepção mais ampla de formação profissional e docente na instituição. Com base nos princípios anteriormente definidos, pretende subsidiar os professores para o exercício da docência, destacando-se aqui a relação teoria e prática e a articulação ensino e pesquisa. $\mathrm{O}$ curso de formação planeja, com isso, propiciar a discussão de fundamentos teóricos para compreender a Universidade Brasileira e a UFG na atualidade e o processo de ensino-aprendizagem que realiza, articulando essa discussão com a eleição de situações-problema que os docentes estão vivenciando no cotidiano dos seus cursos.

\section{EMENTA}

A Universidade no Brasil e a Universidade Federal de Goiás. A estrutura acadêmica da UFG. Tópicos da Didática no Ensino Superior: Diretrizes Curriculares, Projeto político-pedagógico, Planejamento de Ensino, Avaliação da Aprendizagem, Relação Professor-Aluno. Estudos de Caso/situações-problema da prática docente na UFG.

\section{OBJETIVOS}

1. Discutir a Universidade Brasileira e conhecer a estrutura e funcionamento da Universidade Federal de Goiás.

2. Estudar a formação do professor universitário e suas implicações nos processos de ensino e aprendizagem ocorridos na Universidade.

3. Construir conceitos básicos do campo da educação e da Didática e temas relacionados ao exercício profissional do professor no ensino superior

4. Refletir sobre a prática pedagógica no ensino superior tendo como parâmetros a estruturação didática do processo de ensino e seus elementos constitutivos.

\section{CONTEÚDOS PROGRAMÁTICOS}

Introdução/abertura -4 horas

Unidade I- A Universidade Brasileira e a UFG - 8 horas

Unidade II- Tópicos da Didática no Ensino Superior - 28 horas

- Formação pedagógica e a docência na universidade.

- Diretrizes Curriculares e os Cursos de Graduação.

- Projetos Político-pedagógicos dos Cursos de Graduação.

- Planejamento do ensino: um aspecto relevante do trabalho docente na Universidade.

- A relação professor-aluno e o processo ensino-aprendizagem do aluno universitário.

- Avaliação da aprendizagem na educação superior.

Unidade III- Estudo de Caso - situações/problema - 12 horas

Encerramento: Autoavaliação e Avaliação do Curso - 4 horas 
REVISTA ELETRÔNICA

DA GRADUAÇÃO/PÓS-CEADUAÇÃO EM EDJ̈CAÇÃO

UFG/REJ

\section{METODOLOGIA}

As aulas terão como base exposições orais de professores e convidados, leituras prévias individuais realizadas pelos alunos e serão desenvolvidas por meio de diversas atividades de discussão e reflexão sobre os temas estudados, tais como:

1. Trabalhos de sistematização em pequenos grupos;

2. Trabalhos de discussão coletiva (discussão espontânea e dirigida);

3. Aulas expositivas dialogadas.

4. Pesquisa, do tipo estudo de caso, sobre situações/problemas da prática docente na UFG e exposição dos estudos.

\section{AVALIAÇÃo}

A avaliação será contínua, permeando todo o curso, através da observação, acompanhamento e realização de pequenas atividades no decorrer das aulas como textos-síntese sobre os temas, debates, sistematização dos trabalhos de grupo, levantamento de opinião dos professores. Além dessa avaliação, os professores em formação realizarão um trabalho, ao final do curso, a combinar.

Fonte: PROGRAD/UFG (2001)

Diante da análise do Plano de Curso, verifica-se que o Curso de Docência pouco acrescentava aos conhecimentos e à prática docente dos ingressantes, sendo ministrado e cursado apenas para o cumprimento da Resolução CONSUNI No. 001/2001, fornecendo ao docente o certificado a fim de cumprir com as exigências para aprovação efetiva do Estágio Probatório e, assim, ter sua progressão garantida.

$\mathrm{Na}$ íntegra, não se tratava de uma formação de professores, o que para Ferry (1991, apud MARCELO, 1991) deve contemplar uma formação dupla, combinando a formação acadêmica e pedagógica, preparando profissionais que nem sempre se identificam com as características da docência e, sobretudo, contribuir para a formação de formadores, influenciando a correlação entre qualificação de professores e a sua prática profissional.

Influenciados pela produção científica que tratam sobre a formação continuada dos professores universitários, sobretudo a partir da década de 90 e intensificada após o ano 2000, e para se adequar ao disposto na Lei de Diretrizes e Bases da Educação Nacional (LDB - Lei Nº. 9394/96), que define no Art. 63, inciso III, que as instituições formativas deverão manter "programas de formação continuada para os profissionais de educação dos diversos níveis" e, no art. 67, inciso II, que "os sistemas de ensino deverão promover aperfeiçoamento profissional continuado, inclusive com licenciamento periódico remunerado para esse fim” (BRASIL, 1996), 


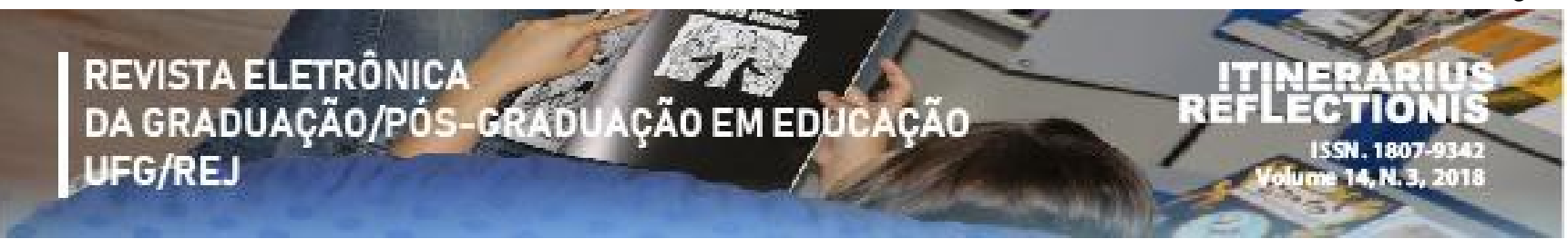

além das duras críticas apresentadas pelos ex-cursistas, a Pró-Reitoria de Graduação, elaborou, em 2006, a política de formação continuada do profissional docente da UFG, denominada Programa de Formação para a Docência no Ensino Superior, composto por cursos e projetos, a saber:

1) Curso: Docência no Ensino Superior/Estágio Probatório (60h);

2) Curso: Docência no Ensino Superior/Formação Permanente (48h);

3) Curso: Docência no Ensino Superior/Professores Substitutos (32h);

4) Curso: Formação em Gestão Acadêmica (48h) destinado a diretores, coordenadores, técnico-administrativos;

5) Projeto: Seminários de Formação na Graduação da UFG (8h), que contempla discentes e docentes de todos os cursos e campi da instituição. (ROSA; CHAVES, 2013)

Diante da reestruturação, que vigorou entre os anos de 2006 a 2013, o Curso de Docência no Ensino Superior destinados a professores em estágio probatório passa a ter uma carga horária de 60 horas, com a inclusão de novos conteúdos voltados à prática docente, elencando ensino pesquisa e extensão, abordando também tecnologias da comunicação e informação, conforme apresentado no Cronograma $(2012-2)^{3}$ na Tabela 2:

Tabela 2 Cronograma: Curso de Docência - Estágio Probatório (2012-2).

\begin{tabular}{lc}
\hline \multicolumn{1}{c}{ TEMA } & CH \\
\hline Unidade I & $4 \mathrm{~h}$ \\
$\begin{array}{l}\text { Abertura do Curso } \\
\text { Apresentação PROGRAD }\end{array}$ & \\
$\begin{array}{l}\text { Apresentação PRPPG, PROEC } \\
\text { Princípios constitucionais que regem a atividade da administração do serviço público } \\
\text { A Universidade Brasileira e a UFG }\end{array}$ & $4 \mathrm{~h}$ \\
$\begin{array}{l}\text { Apresentação da PROAD, PROCOM } \\
\text { Unidade II }\end{array}$ & $4 \mathrm{~h}$ \\
$\begin{array}{l}\text { Didática no ensino superior: Concepção de Ciência e suas implicações no processo } \\
\text { de ensino-aprendizagem }\end{array}$ & $4 \mathrm{~h}$ \\
\end{tabular}

\footnotetext{
${ }^{3}$ Utilizaram-se, para análise, o Cronograma 2012-2 (encontrado na COGRAD - REJ) em consequência da não localização dos Planos de Ensino (2006 a 2013) e dos cronogramas (2006 a 2011), pois todos os documentos eram arquivados na PROGRAD (Goiânia) e, apesar de várias solicitações e buscas, não foram encontrados: os arquivos impressos foram encaminhados ao CIDARQ (Centro de Informação, Documentação e Arquivo) e, os digitais se perderam em virtude dos computadores nos quais os mesmos estavam armazenados sofreram problemas técnicos e não haviam realizados backups preventivos.
} 
REVISTA ELETRÔNICA

DA GRADUAÇÃO/PÓS-GKADULAÇÃO EM EDÜCACÇÃO

UFG/REJ

Apresentação PRPPG

Estudo de Caso - situações/problema

(Introdução e Formação dos Grupos)

Planejamento educacional (PPC)

Planejamento educacional (Plano de Ensino)

Planejamento educacional (Plano de aula e estratégias de ensino)

Avaliação da aprendizagem no ensino superior

Avaliação da aprendizagem no ensino superior

Relação professor/aluno no processo de ensino e aprendizagem no ensino superior

Estudo de Caso - situações/problema (Orientação)

Tecnologias da Comunicação e Informação no processo de ensino e aprendizagem

Estudo de Caso - situações/problema - Apresentação

Autoavaliação e Avaliação do Curso

Fonte: COGRAD/UFG/REJ (2012)
$4 \mathrm{~h}$

$4 \mathrm{~h}$

$4 \mathrm{~h}$

$4 \mathrm{~h}$

$4 \mathrm{~h}$

$4 \mathrm{~h}$

$4 \mathrm{~h}$

$4 \mathrm{~h}$

$4 \mathrm{~h}$

$4 \mathrm{~h}$

No entanto, apesar dos esforços da equipe em se adequar às demandas e às exigências legais, esta reestruturação não obteve êxito, pois além de aumentar a carga horária do curso, a estrutura e as metodologias continuaram idênticas: inflexíveis, tradicionalistas, aulas semanais. Pouco se acrescentou à formação continuada dos novos docentes, persistindo as críticas e provocando desinteresse nos demais professores que ainda teriam que cursá-lo.

Em 2014 (Tabela 3), o Curso Docência no Ensino Superior - Estágio Probatório foi analisado e reestruturado, em cumprimento ao Plano de Gestão e à Resolução CONSUNI Nº. 32/2013, e na tentativa de sanar os anseios e adequar às avaliações dos participantes.

$\mathrm{Na}$ contramão dessas críticas, a defesa de que o curso naquele formato representou um momento muito importante para inserção profissional de um número muito significativo de docentes, jovens pesquisadores, que chegaram à UFG desde 2009, especialmente com a implantação do REUNI. Para os professores que não tinham experiência docente, o curso representou espaço importante para o conhecimento específico dos desafios da atuação em sala de aula, o que justificava a relevância do foco pedagógico do curso. Convém ressaltar que não estava em questão o fim dessa formação, mas sim como fazêla e seu formato. (UFG, 2016)

Diante das críticas apresentadas, como carga horária elevada, curto tempo destinado ao conhecimento da dinâmica institucional e da docência na UFG, pelo foco na formação pedagógica dos docentes, desconsiderando as outras dimensões da docência na educação superior, dentre outras, sobretudo às vindas das Regionais do interior, foi novamente reformulado, passando a ter uma carga horária menor, totalizando 48 horas. No entanto, apesar da 


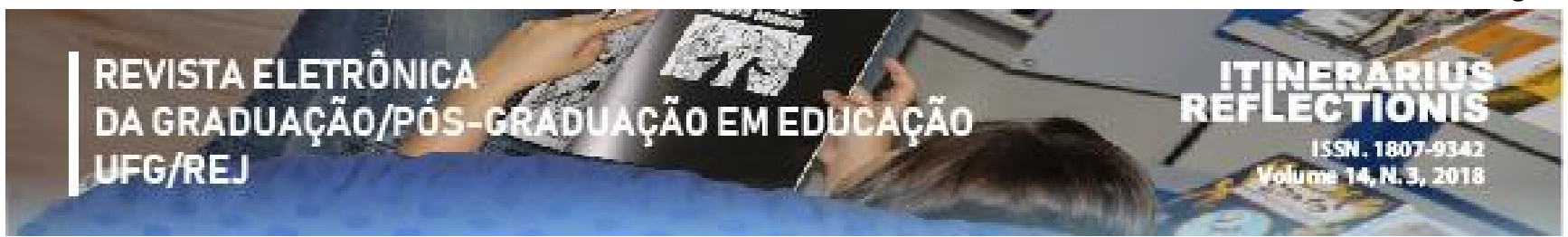

redução da carga horária, o novo formato também foi alvo de muitas críticas por ainda reproduzir as metodologias tradicionais e exigir do cursista, a produção de um artigo científico para a integralização do curso.

Tabela 3: Plano de Curso: Curso de Docência - Estágio Probatório (2014)

Ementa
A Universidade no Brasil e a Universidade Federal de Goiás. Tópicos da Didática no Ensino Superior:
Planejamento Docente, Avaliação da Aprendizagem, Relação Professor-Aluno, Tecnologias da Comunicação e
Informação no Processo de Ensino Aprendizagem. Experiências docentes no ensino superior.

Objetivos

1. Discutir a Universidade Brasileira e a Universidade Federal de Goiás.

2. Estudar a formação do professor universitário e suas implicações nos processos de ensino e aprendizagem ocorridos na Universidade.

3. Refletir sobre a prática pedagógica no ensino superior tendo como parâmetros a estruturação didática do processo de ensino e seus elementos constitutivos.

4. Partilhar as experiências de ensino, pesquisa e extensão desenvolvidas pelos docentes da/na UFG.

\section{Conteúdos Programáticos}

- A Universidade Brasileira e a UFG.

- Ser professor na Universidade: desafios contemporâneos.

- A relação professor-aluno.

- O planejamento docente.

- Avaliação da aprendizagem no ensino superior.

- Tecnologias da comunicação e informação no processo de ensino aprendizagem.

- Conversa de Professores: Partilhando experiências, preocupações, dúvidas, acertos, alegrias.

- Encerramento: Autoavaliação e Avaliação do Curso.

\section{Metodologia}

As aulas terão como base exposições orais de professores convidados, leituras prévias individuais realizadas pelos professores-alunos e atividades de discussão e reflexão sobre os temas estudados, tais como:

${ }_{17}^{35}$ Trabalhos de sistematização em pequenos grupos;

${ }_{17}^{35}$ Trabalhos de discussão coletiva (discussão espontânea e dirigida);

${ }_{17}$ Aulas expositivas dialogadas.

${ }_{17}^{35}$ Partilha de Experiências no Ensino Superior

\section{Avaliação}

A avaliação será contínua, permeando todo o curso, por meio da observação, acompanhamento e realização de pequenas atividades no decorrer das aulas como textos-síntese sobre os temas, debates, sistematização dos trabalhos de grupo, levantamento de opinião dos professores. Além disso, os professores em formação realizarão um trabalho de partilha de experiência docente que será apresentado ao final do curso. 
REVISTA ELETRÔNICA

DA GRADUAÇÃO/PÓS-GRADUAÇÃO EM EDÜCACČ̃̃O

UFG/REJ

Em 2016, a PROGRAD inovou no lançamento de um novo modelo de Curso, com o objetivo de torná-lo atrativo e adequado às exigências (Tabela 4). Salienta-se que apesar da carga horária ser novamente ampliada para 60 horas, à nova estrutura flexível em módulos permite que o docente ingressante a cumpra dentro dos dois primeiros anos de estágio probatório de acordo com suas possibilidades, (exceto os módulos I e II que são obrigatórios no semestre de ingresso e no subsequente); há a implantação: dos sistemas acadêmicos utilizados pela UFG (SIGAA, SAP, SIEC, SICAD); de um módulo à distância para se tratar de assuntos relacionados à tecnologia nos processos educativos e; de um módulo que permite ao cursista a integração nas atividades formativas diversas e culturais promovidas pela instituição.

Tabela 4 Plano de Curso: Curso de Docência - Estágio Probatório (2016)

\section{Programa Formação para a Docência na UFG: objetivos}

O Programa Formação para a Docência na UFG tem como objetivo contribuir para uma maior e melhor inserção dos novos professores da UFG na carreira docente. Para cumprir com esse objetivo, pretende-se:

1. Apresentar a UFG e sua estrutura institucional aos novos docentes;

2. Problematizar questões atinentes à prática pedagógica docente;

3. Criar espaço de diálogo, partilha e troca de experiências entre os docentes;

4. Constituir um canal de interlocução entre a instituição e os docentes.

Nessa perspectiva, o Programa Formação para a Docência na UFG tem uma estrutura mais flexível, com carga horária total de 60 horas, distribuídas em quatro módulos, ao longo dos dois primeiros anos do estágio probatório. O professor deverá fazer todos os módulos obtendo um mínimo de $75 \%$ de frequência em cada um. Nessa nova dinâmica, o primeiro módulo e o segundo módulos serão obrigatórios, respectivamente, no semestre de ingresso e no subsequente, e os demais poderão ser realizados de acordo com a escolha do docente, num período máximo de dois anos, a contar de seu ingresso na UFG.

Nessa nova estrutura a PROGRAD ficará responsável pela organização pedagógica do Programa, e a Prodirh, por meio do DDRH, assumirá a parte logística: contato com os professores, controle da frequência, divulgação das atividades que compõe o Módulo 4 e organização dos espaços.

Por fim, compreendemos que o Programa Formação para a Docência na UFG também poderá contemplar a formação continuada dos docentes da UFG, com oferta de vagas das atividades em curso para todos os docentes, mas também propondo novas atividades formativas para atender demandas específicas dos docentes da UFG.

\section{Estruturação do Programa Formação para a Docência na UFG - 60h}

A estrutura do Programa Formação para a Docência na UFG está organizada em quatro módulos:

\section{Módulo 1 - Nossa UFG: Espaço Aberto para Você (16h)}

No semestre de ingresso, o docente inicia sua formação com o primeiro módulo, "Nossa UFG: Espaço Aberto para Você", que tem duração de 16 horas, distribuídas em quatro encontros. Esse módulo objetiva permitir que o docente conheça a instituição: seu projeto institucional, organização, estrutura e dinâmica de 


\section{REVISTA ELETRÔNICA \\ DA GRADUAÇÃO/PÓS-GKADUAÇÃO EM EDỦCAÇ̄̃̃ \\ UFG/REJ}

funcionamento; a política de ensino, pesquisa, extensão e cultura; o perfil dos estudantes que estão na UFG; e os principais sistemas que utilizará nos diversos âmbitos de atuação profissional: Sistema Integrado de Gestão Acadêmica (SIGAA), Sistema de Cadastro de Atividade Docente (SICAD), Sistema de Acompanhamento de Pesquisas (SAP), Sistema de Informações de Extensão e Cultura (SIEC). Esse módulo será ofertado semestralmente, a partir de 2016/1.

\section{Módulo 2 - Vivências Pedagógicas (16h)}

O Módulo 2, "Vivências Pedagógicas", tem duração de 16 horas e pretende problematizar questões atinentes à prática docente: ser docente na universidade, relação professor-aluno, planejamento, metodologia $\mathrm{e}$ avaliação. O módulo será ofertado semestralmente, a partir de 2016/1.

\section{Módulo 3 - Docência em Tempos Tecnológicos (16h)}

O Módulo 3, "Docência em Tempos Tecnológicos", tem duração de 16 horas, com 12 horas na modalidade a distância e apenas o primeiro encontro presencial. Pretende-se discutir questões relativas ao uso de novas tecnologias de comunicação no trabalho docente e suas repercussões sobre a definição clássica de sala de aula: celular, jogos, redes sociais, Moodle e SIGAA. Também pretende-se discutir a educação a distância como modalidade e sua utilização no ensino presencial. O módulo será estruturado a partir de parceria com os órgãos e laboratórios que trabalham com tecnologias e educação a distância, tais como o Centro Integrado de Aprendizagem em Rede (Ciar), o Centro de Recursos Computacionais (Cercomp) entre outros, e será ofertado semestralmente.

\section{Módulo 4 - Tempo de Debate (12h)}

O Módulo 4, "Tempo de Debate", tem duração de 12 horas e pretende oferecer aos docentes uma maior inserção nas atividades formativas que a UFG realiza: congressos, seminários, palestras, apresentações artísticas e culturais. Esse módulo é de oferta livre, ou seja, todos os envolvidos no processo podem realizar propostas de atividades: a coordenação do Programa pode organizar e indicar atividades para compor o conjunto desse módulo; os docentes recém-ingressos podem propor atividades, que em consonância com sua atuação, contribuam na formação de todos. Para exemplificar, a coordenação do Programa recebeu uma proposta de formação sobre o Sistema Único de Saúde e outra sobre Gênero, Sexualidade e Educação, que estão incorporadas na proposta e poderão ser ofertadas aos novos professores da UFG.

Nesse módulo, aproveitando uma experiência já realizada na Universidade Federal do Ceará, pretendese também organizar o "Espaço das Experiências", com sessões de homenagens aos nossos Mestres de Referências, ou seja, um professor escolhido pelos docentes ou pela coordenação do Programa, que, por sua trajetória na docência no ensino superior, é considerado como um Mestre, e sua experiência pode contribuir para o aprendizado dos novos docentes em formação.

Fonte: PROGRAD/UFG (2016)

Dessa maneira, o Curso de Docência, no ano de realização deste estudo, se constitui como uma ação de acolhimento aos novos professores da UFG, com o intuito de possibilitar sua inserção na carreira docente (UFG, 2016) e para o cumprimento do disposto no Art. $8^{\circ}$ da Resolução CONSUNI No. 32/2013, que "dispõe sobre normas para avaliação de pessoal docente em relação ao estágio probatório, à progressão funcional e à promoção na Carreira do Magistério Superior, e revoga as disposições em contrário”, o qual estabelece: 
Art. $8^{\circ}$ Ao tomar posse, o docente deverá participar do programa de atividades relativas à política de ensino, pesquisa, extensão, gestão acadêmica e sua inserção na realidade da UFG, promovidas e regulamentadas pela Pró-Reitoria de Graduação - PROGRAD e pela Pró-Reitoria de Desenvolvimento Institucional e Recursos Humanos - PRODIRH. $\S 1^{\circ}$ A comprovação de participação nas atividades de que trata o caput deste artigo integrará a avaliação a que se refere o artigo anterior.

$\S 2^{\circ}$ A realização das atividades exigidas no caput deste artigo é condição indispensável para finalização do estágio probatório. (UFG, 2013)

Assim, o novo formato do Curso de Docência,

Representa, por um lado, um esforço com vistas à ampliação da formação dos novos docentes que ingressam na instituição, muitos dos quais, jovens com trajetórias consolidadas no campo da pesquisa, mas sem formação específica para atuar no magistério e/ou com pouca experiência profissional como professor. Por outro, representa uma resposta institucional às sugestões feitas por ex-participantes de turmas anteriores do já tradicional curso de Formação Docente - Estágio Probatório. (UFG, 2016)

O Curso de Docência - Estágio Probatório, desde a sua criação, em 2001, até o ano de 2013, foi promovido na Regional Jataí, assim como nas demais regionais, exclusivamente pela equipe da PROGRAD. Todos os processos de elaboração, preparação e execução ficavam a cargo da Regional Goiânia, excluindo qualquer tipo de autonomia à Regional.

Toda a comunicação era feita diretamente com o Diretor, o qual encaminhava ao setor responsável, até o momento do presente estudo denominada Coordenação de Graduação (COGRAD), para o auxílio na divulgação do curso e no preparo das salas de aula para o cumprimento dos cronogramas estipulados. Assim, a função da COGRAD era apenas de auxiliar na logística da execução das aulas, contribuindo com o suporte técnico.

Da mesma forma, todos os documentos relativos aos Cursos produzidos na Regional Jataí nos diferentes anos, eram encaminhados à PROGRAD, até mesmo as listas de frequências, o que demonstrava a falta de autonomia e, por fim ocasionou a ausência de dados e de documentos para o presente estudo, Não há arquivos na COGRAD e a PROGRAD não os disponibilizou alegando não tê-los, em virtude de envios de documentos antigos ao Centro de Informação, Documentação e Arquivo (CIDARQ), localizado na Regional Goiânia, e perdas dos documentos digitais devido à problemas técnicos nos computadores ou por falta de backups. 
REVISTA ELETRÔNICA

DA GRADUAÇÃO/PÓS-CEADUAÇÃO EM EDÜCAÇÃO

UFG/REJ

No entanto, a partir de 2014, esse cenário começou a sofrer alterações. Pela primeira vez, após vários pedidos e apresentações das queixas recorrentes sobre o Curso, certa autonomia foi concedida a então Coordenadora dos Cursos de Jataí, a qual incluiu o histórico da Regional Jataí na apresentação da estrutura da UFG e a participação de servidores da própria Regional para ministrar o Curso de Docência no Ensino Superior aos professores aqui lotados. Assim, no ano de 2014, o curso foi ministrado por 11 professores e 01 técnico-administrativo da Regional Goiânia e, por 10 professores e 5 técnicos administrativos da Regional Jataí.

Neste mesmo ano: a programação foi elaborada pela PROGRAD e cumprida pela Regional Jataí integralmente; a COGRAD também adquiriu autonomia para gerir e arquivar os documentos, desde as fichas de inscrições até coleta das listas de frequência; elaborou, aplicou e sistematizou os dados referentes à avaliação do curso; elaborou a folha de pagamento dos servidores de Jataí, tendo uma participação atuante e, a comunicação passou a ser feita diretamente entre os setores envolvidos. Quanto à gestão dos documentos, apesar da autonomia concedida, a emissão dos certificados ainda ficou a cargo da equipe da Regional Goiânia.

Apesar de estar descrita sucintamente a metodologia e a avaliação no penúltimo encontro, a saber: “...Além da apresentação oral será pedida a entrega da 'Conversa' por escrito. Os professores terão a liberdade de apresentar o trabalho no formato que quiserem: artigo, monografia, poesia, conto, história de vida etc. O objetivo geral é oferecer a todos liberdade de criação", na prática, foi exigido a entrega de um artigo coletivo para fins de avaliação, o que gerou críticas e repercussão negativas.

No ano de 2015, a partir das conquistas do ano anterior e da nova postura da PROGRAD, foi concedida à Regional Jataí maior autonomia. Apesar de mantida a estrutura do Curso elaborada pela PROGRAD, a COGRAD teve a liberdade para acrescentar temas novos aos conteúdos e adotou outras metodologias, como: mesa redonda, apresentação e utilização do Moodle como ferramenta de ensino, apresentação de metodologias ativas, troca de experiências e debates, o que amenizou relativamente as críticas.

Merece aqui destacar, que além do acréscimo de novos temas, no referido ano, houve a apresentação da estrutura da Regional Jataí com destaque às coordenações administrativas e assessorias, fato inédito, visto que em nos anos retroativos, somente a estrutura da Regional Goiânia era apresentada. 
REVISTA ELETRÔNICA

DA GRADUAÇÃO/PÓS- CRA DUUAÇÃO EM EDÜCAÇÃO

UFG/REJ

Outro fato que merece destaque é o fato do Curso ter sido ministrado por uma equipe de 12 servidores, sendo 10 servidores da Regional Jataí (10 docentes e 1 técnico administrativo) e por apenas dois professores da Regional Goiânia.

E, na tentativa de amenizar as críticas quanto à produção do artigo científico, foi proposto como trabalho final de curso a realização de partilha de experiências entre os participantes, a qual foi muito bem aceita e elogiada pelos professores cursistas.

No último curso de formação de docentes organizado pela COGRAD, no ano de 2016 (Tabela 5), por causa de uma nova proposta política da PROGRAD, foi dada total autonomia à Regional Jataí para planejar e executar suas ações no que tange ao Curso de Docência no Ensino Superior - Estágio Probatório. Diante deste panorama, a equipe da COGRAD adequou o programa estabelecido pela PROGRAD para o ano de 2016 às realidades da Regional, com o intuito de tornar o Curso de Docência mais atrativo, prático, reflexivo à sua prática profissional docente na UFG-REJ. Para tanto, tinha como objetivos:

- Apresentar e discutir a Universidade Federal de Goiás e a Regional Jataí.

- Expor e debater a Resolução 32/2013 que dispõe sobre normas para avaliação de pessoal docente em relação ao estágio probatório, à progressão funcional e à promoção na Carreira do Magistério Superior.

- Refletir sobre a prática pedagógica no ensino superior tendo como parâmetros a estruturação didática do processo de ensino e seus elementos constitutivos.

- Instruir quanto ao uso dos sistemas acadêmicos da UFG.

- Contribuir na integração e na formação continuada dos docentes, envolvendo-os em eventos promovidos pela Regional Jataí. (UFG, 2016)

O curso teve uma carga horária de 50 horas, sendo 38 horas teórico-práticas e 12 horas de Atividades Complementares, as quais foram cumpridas por meio da participação em eventos científicos voltados à formação de professor e de apresentações artísticas e culturais promovidos pela REJ, durante o período de estágio probatório e à escolha do docente. As 38 horas foram divididas em três módulos presenciais em que tinham os seguintes conteúdos: A Universidade Federal de Goiás e a Regional Jataí, Estágio Probatório (Resolução 32/2013), Assédios no trabalho, Tópicos da Didática no Ensino Superior: Planejamento Docente, Avaliação da Aprendizagem, Relação Professor-Aluno, Metodologias e Sistemas Acadêmicos. 


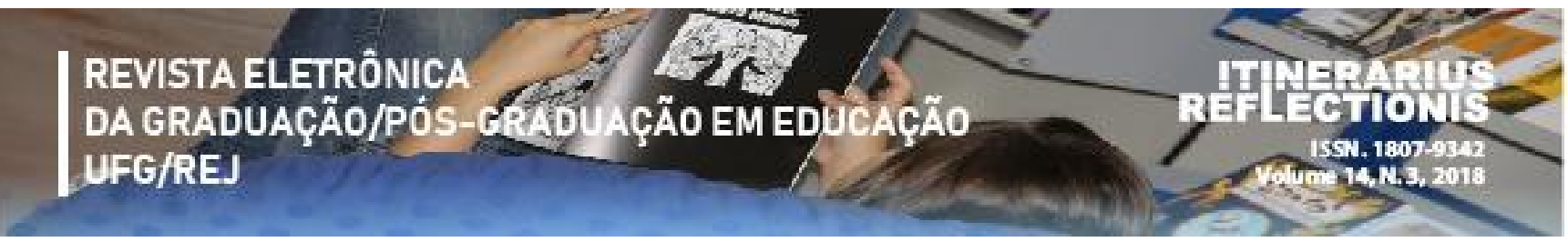

Atendendo às solicitações, o curso foi ofertado de modo condensado, em cinco sextas-feiras (período integral) nos meses de outubro e novembro e contou com a participação exclusiva de servidores veteranos da REJ que ministraram dos conteúdos. O Curso foi divulgado pela equipe da COGRAD e pela Assessoria de Comunicação (ASCOM) a todos os professores da Regional Jataí, não apenas aos que estão em estágio probatório, tendo uma repercussão positiva em relação à nova estrutura e dinâmica do curso em questão.

Tabela 5 Plano de Curso: Curso de Docência - Estágio Probatório - REJ (2016)

\section{Exposição de motivos}

O Programa de Docência no Ensino Superior na UFG - Regional Jataí (Estágio Probatório) é uma proposta de constituição de um espaço de acolhida aos novos professores da Regional Jataí da UFG, visando possibilitar sua inserção na carreira docente. Será desenvolvido conjuntamente pela Coordenação de Graduação (COGRAD) e pela Coordenação de Desenvolvimento Institucional e Recursos Humanos (CODIRH), pela com vistas ao cumprimento do art. 8 da Resolução CONSUNI n". 32/2013, que "dispõe sobre normas para avaliação de pessoal docente em relação ao estágio probatório, à progressão funcional e à promoção na Carreira do Magistério Superior, e revoga as disposições em contrário", o qual estabelece:

Art. $8^{\circ}$ Ao tomar posse, o docente deverá participar do programa de atividades relativas à política de ensino, pesquisa, extensão, gestão acadêmica e sua inserção na realidade da UFG, promovidas e regulamentadas pela Pró-Reitoria de Graduação - PROGRAD e pela Pró-Reitoria de Desenvolvimento Institucional e Recursos Humanos - PRODIRH.

$\S 1^{\circ}$ A comprovação de participação nas atividades de que trata o caput deste artigo integrará a avaliação a que se refere o artigo anterior.

$\S 2^{\circ}$ A realização das atividades exigidas no caput deste artigo é condição indispensável para finalização do estágio probatório. (UFG, 2013)

Assim, o Programa Docência no Ensino Superior na UFG - Regional Jataí (Estágio Probatório) representa, por um lado, um esforço com vistas à ampliação da formação dos novos docentes que ingressam na instituição, muitos dos quais, jovens com trajetórias consolidadas no campo da pesquisa, mas sem formação específica para atuar no magistério e/ou com pouca experiência profissional como professor. Por outro, representa uma resposta institucional às sugestões feitas por ex-participantes de turmas anteriores do já tradicional curso de Formação Docente - Estágio Probatório, criado em 1994 e com várias mudanças ao longo das últimas décadas.

Quando a atual gestão da UFG (2014-2017) tomou posse, em consonância como Plano de Gestão proposto pelos professores Orlando Afonso Valle do Amaral e Manoel Rodrigues Chaves $^{4}$, foi colocada em discussão, no âmbito da equipe gestora, uma proposta de reestruturação do curso. Essa reestruturação estava pautada pela avaliação de ex-participantes de que o curso tinha carga horaria muito extensa, com pouco tempo destinado ao conhecimento da dinâmica institucional da UFG e da docência nessa universidade, e pelo foco muito voltado para a formação pedagógica dos docentes, desconsiderando as outras dimensões da docência na

\footnotetext{
${ }^{4} \mathrm{O}$ tema havia sido debatido durante a campanha para a gestão da reitoria da UFG em 2013 e passou a constar como uma das propostas do plano de ação da gestão.
} 


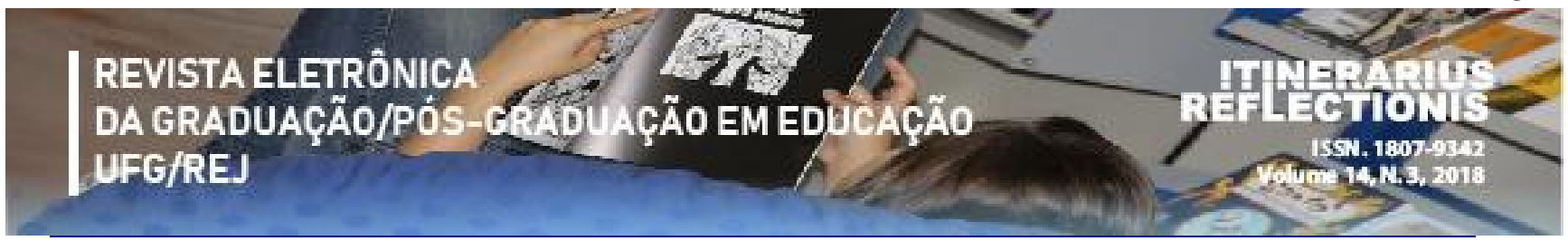

educação superior. Na contramão dessas críticas, a defesa de que o curso naquele formato representou um momento muito importante para inserção profissional de um número muito significativo de docentes, jovens pesquisadores, que chegaram à UFG desde 2009, especialmente com a implantação do REUNI. Para os professores que não tinham experiência docente, o curso representou espaço importante para o conhecimento específico dos desafios da atuação em sala de aula, o que justificava a relevância do foco pedagógico do curso. Convém ressaltar que não estava em questão o fim dessa formação, mas sim como fazê-la e seu formato.

Com esse desafio, uma proposta de reestruturação do curso foi implementada, no ano de 2014, mas as avaliações ainda destacaram as dificuldades em fazer um curso semanal, ao longo de todo o semestre, e a crítica sobre o foco recair ainda, em grande medida, na dimensão pedagógica, desconsiderando outros aspectos centrais para a inserção dos novos professores na UFG.

É nesse contexto de reconhecimento da relevância do curso, mas também da necessidade de definição de novos formato e conteúdos, que aqui se apresenta a proposta de transformação do curso em um programa de formação mais amplo, que busque atender aos anseios dos docentes que ingressam na UFG-REJ, de conhecer essa universidade, sua identidade institucional, mas também que contribuía para a inserção dos novos profissionais na carreira docente, contemplando atividades no âmbito do ensino, pesquisa, extensão e gestão.

\section{Objetivos}

O Programa Docência no Ensino Superior na UFG - Regional Jataí (Estágio Probatório) tem como objetivo contribuir para uma maior e melhor inserção dos novos professores da Regional Jataí na carreira docente. Para cumprir com esse objetivo, pretende-se:

1. apresentar a UFG e a Regional Jataí bem como a estrutura institucional aos novos docentes;

2. problematizar questões atinentes à prática pedagógica docente;

3. criar espaço de diálogo, partilha e troca de experiências entre os docentes;

4. constituir um canal de interlocução entre a instituição e os docentes.

Nessa perspectiva, o Programa Docência no Ensino Superior na UFG - Regional Jataí (Estágio Probatório) tem uma estrutura mais flexível, com carga horária total de 50 horas, distribuídas em quatro módulos. O professor deverá fazer todos os módulos obtendo aproveitamento satisfatório e um mínimo de 75\% de frequência em cada um.

No ano de 2016, COGRAD ficará responsável por toda organização do curso (pedagógica, administrativa e logística) e a CODIRH ficará responsável pela divulgação das atividades que compõem o Módulo IV.

Por fim, compreendemos que o Programa Docência no Ensino Superior na UFG - Regional Jataí (Estágio Probatório) também poderá contemplar a formação continuada dos docentes da referida instituição, com oferta de vagas das atividades em curso para todos os docentes, mas também propondo novas atividades formativas para atender demandas específicas dos docentes desta Regional.

\section{Estrutura}

O Programa Docência no Ensino Superior na UFG - Regional Jataí (Estágio Probatório) tem carga horária total de 50 horas e está estruturado em quatro módulos.

Módulo 1 - Nossa UFG - REJ (12h)

O docente inicia sua formação com o primeiro módulo Nossa UFG - REJ, que tem duração de 12 horas, distribuídas em três encontros. Esse módulo objetiva permitir que o docente conheça a instituição: seu 
projeto institucional, organização, estrutura e dinâmica de funcionamento; a política de ensino, pesquisa, extensão e cultura; o perfil dos estudantes que estão na UFG-REJ e as políticas de cotas e as ações afirmativas.

Módulo 2 - Relações humanas e práticas pedagógicas (12h)

$\mathrm{O}$ Módulo 2 tem duração de 12 horas e pretende problematizar questões atinentes à prática docente: ser docente na universidade, relação professor-aluno, planejamento, metodologias e avaliação.

Módulo 3 - Sistemas Acadêmicos (14h)

Neste módulo, cuja a duração é de 14 horas, ocorrerá em formato de aulas práticas sobre os principais sistemas acadêmicos que o professor utilizará nos diversos âmbitos de atuação profissional: Sistema Integrado de Gestão Acadêmica (SIGAA), Sistema de Cadastro de Atividade Docente (SICAD), Sistema de Acompanhamento de Pesquisas (SAP), Sistema de Informações de Extensão e Cultura (SIEC).

\section{Módulo 4 - Atividades Complementares (12h)}

O Módulo 4 tem duração de 12 horas e pretende oferecer aos docentes uma maior inserção nas atividades integração e de formação continuada que a UFG realiza, como: congressos, seminários, palestras, conferências, mesas redondas, oficinas voltadas exclusivamente à área de Formação de Docente e apresentações artísticas e culturais.

Os professores da UFG-REJ poderão participar de atividades de formação continuada oferecidas nas Regionais da Universidade Federal de Goiás, desde que apresentem certificados devidamente assinados e contendo os seguintes dados: nome do participante, nome do evento, local e data de realização, carga horária cumprida.

Na contabilização da carga horária deste módulo, considerar-se-á uma carga horária máxima de 4 horas relativas às apresentações artísticas e culturais.

Serão validados os certificados com data retroativa, desde que sejam posteriores à data de posse como docente na UFG-REJ.

Os certificados deverão ser entregues na Coordenação de Graduação, apresentando os originais e as respectivas cópias ( 1 cópia de cada), as quais serão autenticadas e arquivadas para a certificação após o cumprimento de todo os módulos.

Este módulo é de oferta livre, possibilitando aos envolvidos proporem e realizarem atividades para compor o conjunto deste módulo desde que contribuam com a formação pedagógica de todos.

Fonte: COGRAD/UFG/REJ (2016)

Como não foi possível ter acesso aos dados dos docentes participantes da Regional Jataí no Curso de Docência no Ensino Superior - Estágio Probatório desde a sua criação, apresenta-se apenas dados a partir do ano de 2010.

Desde o ano de 2010, somente na Regional Jataí, 208 professores participaram do curso em cumprimento ao disposto nas resoluções que tratam sobre o Estágio Probatório dos Docentes na UFG e, no período compreendido de 01 de janeiro de 2010 a 17 de agosto de 2016, foram admitidos 203 professores efetivos (destes, apenas 175 estão ativos atualmente) conforme dados 


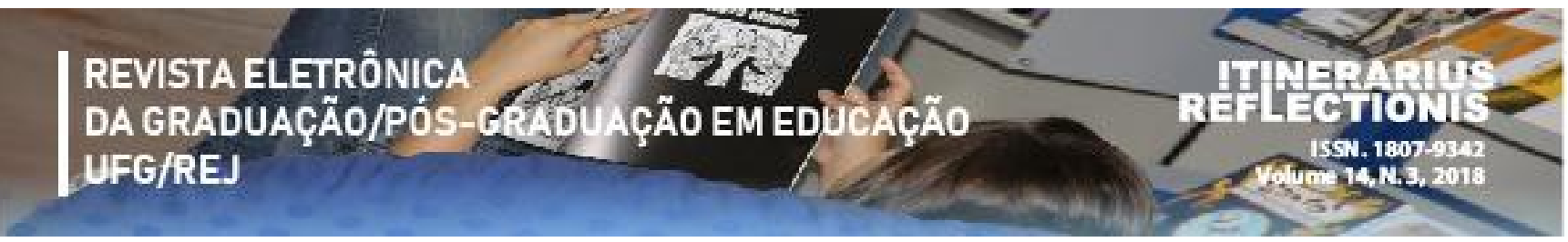

apresentados na Figura 1. Em 2013, não houve o Curso de Docência no Ensino Superior na REJ, pois apenas 4 professores se inscreveram, sendo o curso suspenso.

Figura 1- Quantidade de docentes empossados e participantes dos Cursos de Docência nos anos de 2010 a 2016 na Regional Jataí.

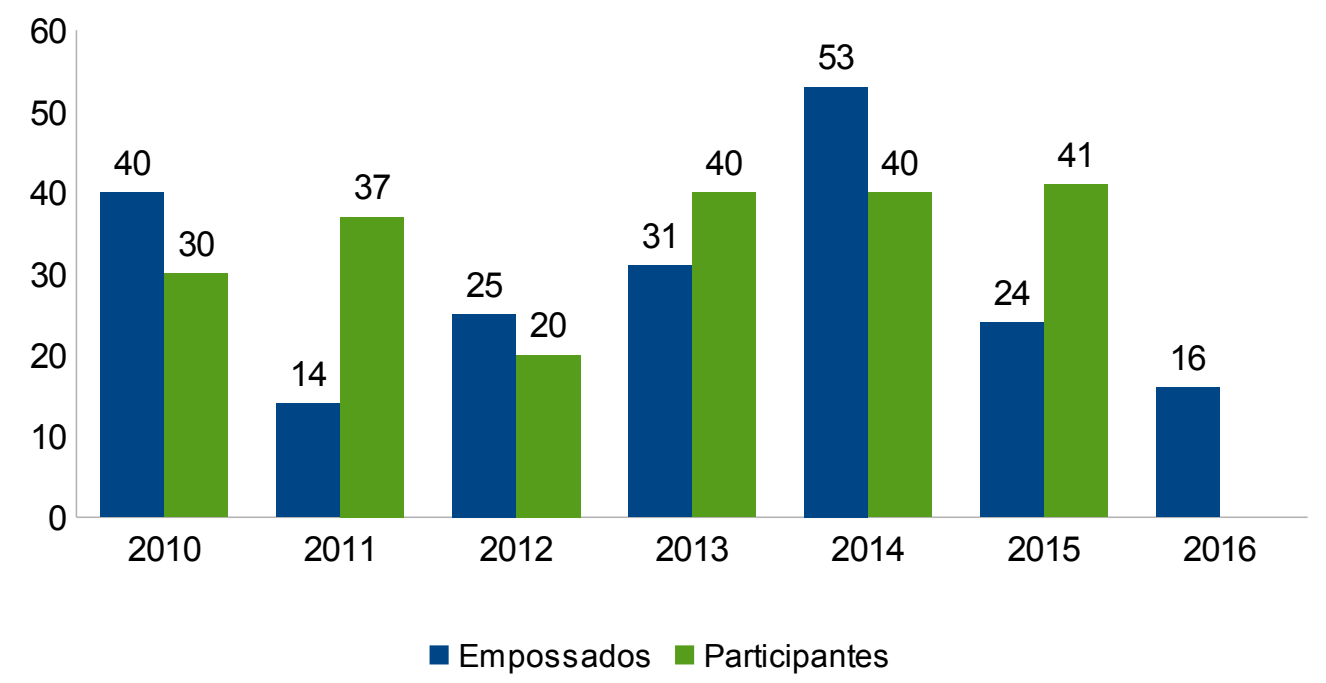

Fonte: os autores (2016)

A análise do gráfico permite concluir que parte dos docentes recém-admitidos não participa do curso no ano de ingresso na UFG, de forma que é prejudicial ao curso e ao próprio professor, gerando críticas por parte do mesmo quando de sua participação. Tal cenário é bastante recorrente nos comentários descritos na Avaliação do Curso, sendo considerado como um ponto fraco, causando desmotivação e uma visão errônea dos objetivos e dos conteúdos abordados.

Ainda quanto às críticas, a análise dos relatórios de avaliação referente aos anos de 2014 e 2015, aponta os seguintes pontos, resumidamente:

\section{Pontos fracos:}

- Carga horária extensa

- Aulas teóricas e expositivas

- Conteúdos repetitivos e sem inovação à prática docente 
REVISTA ELETRÔNICA

DA GRADUAÇÃO/PÓS-CRADUAÇÃO EM EDÜCAÇÃO UFG/REJ

- Apresentação da estrutura da UFG muito longa

- Conteúdos apresentados por docentes de Goiânia, pois eles possuem visão incompleta da realidade da Regional Jataí

- Metodologias inadequadas

- Ser obrigatório

Pontos fortes:

- Empenho da equipe da COGRAD na organização e realização do Curso

- Oportunidade de integração com professores vinculados aos demais Cursos de Graduação

- Troca de experiências e compartilhamento de ideias relacionadas às metodologias ativas

- Cumprimento dos objetivos

- Adoção de metodologias ativas

- Conhecimento do histórico e da estrutura da UFG e da Regional Jataí

Também são apresentadas algumas sugestões, a saber:

- Abordagem de assuntos de interesse do docente

- Caráter prático, valorizando a atuação docente e permitindo ajustes na prática profissional

- Oficinas sobre os sistemas acadêmicos da UFG e plataformas

- Utilização de tecnologias, não ficando apenas na teoria

- Ser ministrado por servidores da Regional Jataí

- Reestruturar o curso para que seja atrativo

Foi com base nas sugestões e nas análises dos pontos fortes e fracos que o Curso de Docência no Ensino Superior - Estágio Probatório 2016 foi reformulado e planejado com intuito de romper a percepção negativa que é repassada aos participantes, adequando às realidades da Regional Jataí e às necessidades atuais de formação continuada de seus novos docentes, motivando-os a cursá-lo na busca de aquisição ou atualização de conhecimentos e práticas pedagógicas, indo além do mero cumprimento de uma obrigação burocrática para conclusão do período de estágio probatório. De fato, a nova proposta foi muito bem recebida! A cada módulo foram distribuídas fichas para avaliação das palestras ou das atividades práticas. Todas as palestras foram muito bem avaliadas, na média com conceitos "ótimo" ou "bom" e as atividades práticas contaram com a participação ativa dos docentes, com avaliações majoritariamente no 
REVISTA ELETRÔNICA

DA GRADUAÇÃO/PÓS- LEADUAÇÃo EM EDÜCAÇÃO

UFG/REJ

nível de "ótimo". Dessa forma, podemos inferir que o novo formato do curso, com mais atividades e aulas práticas, foi muito satisfatória em relação às necessidades dos docentes.

\section{CONSIDERAÇÕES FINAIS}

Concluímos que ficou evidente a importância da análise das críticas dos docentes para a construção de modelos de formação para o ensino superior e esperamos que as análises apresentadas sirvam de instrumento para a proposta de estratégias de formação docente para o grupo gestor da futura Universidade Federal de Jataí. De forma mais específica, concluímos que a evolução do modelo do curso, baseada nas necessidades e nos anseios dos docentes ingressantes na Universidade, para modelos mais práticos e mais focados na experiência diária do docente foi importante para motivar a participação dos docentes e realmente adicionar valores na formação do ingressante. Além disso, pela análise dos critérios que tratam da política de formação e capacitação docente, do Eixo 4 - Políticas de Gestão, do Instrumento de Avaliação Institucional Externa do Ministério da Educação que subsidia os atos de credenciamento, recredenciamento e transformação da organização acadêmica (presencial) consideramos que a Regional Jataí, no período do estudo (2016) satisfez essa exigência, em virtude da "[...] política formação e capacitação docente está prevista/implantada, de maneira suficiente, considerando, em uma análise sistêmica e global [...]”.

\section{REFERÊNCIAS BIBLIOGRÁFICAS}

BRASIL. Lei de Diretrizes e Bases da Educação Nacional - Lei n. 9394 de 20 de dezembro de 1996.

MARCELO, Garcia. Formação de Professores: para uma mudança educativa. Portugal: Porto, 1991.

MEDEIROS, S. Analise swot de uma instituição de ensino: descubra suas fraquezas e oportunidades. Disponível em: <http://5seleto.com.br/analise-swot-de-uma-instituicao-deensino-descubra-suas-fraquezas-e-oportunidades/ >. 2016.

MINISTÉRIO DA EDUCAÇÃO. Instrumento de Avaliação Institucional Exterma, 2014.

ROSA, Dalva Eterna Gonçalves; Chaves, Sandra Mara Matias. Formação pedagógica do professor universitário: uma reflexão sobre a proposta da UFG. Inter-Ação, Goiânia, v. 38, n. 1, p. 169-187, jan./abr. 2013. 


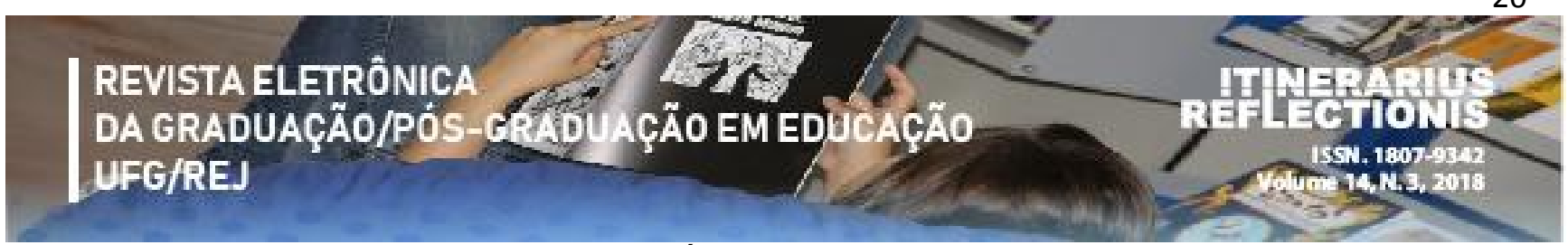

UNIVERSIDADE FEDERAL DE GOIÁS. Dispõe sobre normas para avaliação de pessoal docente em relação ao estágio probatório e em relação à progressão funcional, revogando-se as Resoluções CCEP n ${ }^{\circ}$ 338, 358, 381, 386 e CONSUNI Nº 08/2003. Resolução nº. 001, de 23 de março de 2001.

UNIVERSIDADE FEDERAL DE GOIÁS. Resolução no . 032, de 27 de setembro de 2013. Dispõe sobre normas para avaliação de pessoal docente em relação ao estágio probatório, à progressão funcional e à promoção na Carreira do Magistério Superior, e revoga as disposições em contrário. Goiânia: UFG, 2013.

UNIVERSIDADE FEDERAL DE GOIÁS. Pró-Reitoria de Graduação. Curso: Docência no ensino superior - estágio probatório. Disponível em: <https:/PROGRAD.ufg.br/n/16048-cursodocencia-no-ensino-superior-estagio-probatorio>. Acesso em: 10 maio 2016.

UNIVERSIDADE FEDERAL DE GOIÁS. Pró-Reitoria de Graduação. Programa de formação para a docência na UFG. Disponível em: <https://ddrh.ufg.br/up/123/o/ProgramaFormacao_PRODIRH_PROGRAD.pdf>. Acesso em 12 maio 2016, 